Session \#2793

\title{
Pedagogical Choices in Engineering Curriculum: Traditional and Weekend Format Master's Degree Programs
}

\author{
Carrie E. Girstantas, William T. Scherer \\ University of Virginia
}

\section{Introduction}

One way to meet the increasing demand for experienced and educated professionals in engineering and technology based fields is the formation of degree programs that are concurrent with full time professional work, such as "weekend degree programs". Academic institutions have a challenge to balance the demand for presenting the most current research in a rapidly changing and growing work place while maintaining the integrity of quality engineering curriculum.

The Department of Systems Engineering at the University of Virginia initiated a Master's program in a weekend format in the fall of 1999, called the Executive Master's Degree Program. The general content of the systems engineering curriculum is the same for both the traditional "on-grounds" program and the weekend degree program. This paper highlights some of the pedagogical choices by way of a general taxonomy that the two different educational settings provide for professional engineers.

This paper will frame similarities and differences within each educational experience that are related to characteristic elements of the structures in each degree program. This paper will compare educational elements and their outcomes specific in a Data Mining course with the two different class formats. Also, this paper will discuss further areas of research in engineering education, namely to highlight some of the possibilities that different course and curriculum formats can afford with respect to use of time, technology, and faculty.

General Program Design: Traditional vs. Weekend

In general, a traditional "on-grounds" Master's degree program student enrolls full time, however the format is flexible enough to enroll other kinds of students. Although the individual courses can vary, most traditional academic settings schedule class meetings several times a week for either 50 or 75 minutes, with most exposure to content occurring in lectures. Integration of material and assessment most commonly takes the form of problems sets, laboratory exercises, exams of various types, with some limited use of various types of cases ${ }^{1}$. Most assignments are individually completed and presented, and more in-depth contact occurs with an individual professor usually within a specific to predetermined research interest. 
On the other hand, the weekend format is designed for a student engaged in full time professional position that poses different constraints (i.e. availability of time and energy) and objectives of students while pursuing a Master's degree. The curriculum was developed by systems engineering faculty in consultation with faculty of the Darden Graduate School of Business Administration and an executive advisory board.

Constraints on time and resources impose some structural differences in the design of the curriculum, while providing other opportunities to meet these alternative learning needs and objectives. The program consists of ten courses and a Friday evening seminar, where four courses are the same "core" common to the traditional program and the remaining courses are cohort-selected electives. The program is residential and courses run on alternating weekends over the course of 20 months, with the same cohort of 20-30 students for the duration of the program (http://www.executivemasters.com/).

Several universities have implemented programs with a similar pedagogy and program design. These programs vary in the focus of the content and serve different portions of a broad emerging technological leadership. They include the MBA Program from William and Mary, MIS Program from American University and MSE Program from The University of Pennsylvania. Like UVa, these programs have an alternating weekend format to meet that needs of active professionals in a single cohort for the entire learning experience. The Executive Master's Program in Systems Engineering at UVa is one most theoretically and analytically oriented programs in existence among the programs due to its focus on engineering principles and decision analytics.

Additionally, all these programs are geared toward emerging leaders in the various technological fields and some are choosing to use the weekend format to meet the growing demand for analytically and technologically informed decision makers. The goal is to structure a degree program that meets the rigorous technical requirements of an engineering school as well as the fast-paced demand of a rapidly developing professional. One of the primary educational objectives while pursuing a Master's Degree in Engineering is to deepen and integrate basic analytical principals and then to offer state of the art tools, methodologies, and technologies for the current issues.

Weekend Format Pedagogy

The unique pedagogical design of this program is achieved through the integration of systems engineering methodology into a cohesive curriculum, implemented through case-based, team-oriented learning. The content of the program has a strong focus on the integration of engineering analytical tools, information technological skills, and business issues firmly grounded with a common core of systems engineering. Furthermore, the professional experience base of the student cohort is incorporated into the class discussions and exercises, thus enriching the instruction of applications and methods for the entire cohort.

The 1984 ASEE report "Engineering Education for a Changing World" highlighted the issue of rapid technological changes ${ }^{2}$. The report suggested that 
engineering education institutions look to and take cues from initiatives in the business world. The report emphasizes the need for backward and forward integration between engineering schools, high schools, and industry. These closer partnerships would bring relevance in the engineering curriculum and balance the tendency for schools to focus on theory and research by putting them in touch with the needs of industry and the aspirations of future students. A dynamic dialogue between academic institutions and industry is especially useful at the Master's level of education as well.

\section{Overall Program Summary Comparison:}

Summarized below are some characteristic features of the weekend format Master's Degree Program generally compared to traditional programs. These general qualities and differences serve to frame some of the dimensions of pedagogical choices related to the learning objectives related to the student and the future or current professional context.

Integrated within professional organization $v$ s. individual personal development: the systems engineering program using a weekend format schedule provides an opportunity for a professional with a high level of commitment to their company to pursue their development within that context. Rather than obligations competing for the attention and time of a professional, there is the potential for a synergy of work experience supporting academic learning and vice versa. Furthermore, as concepts and skills are developed through the engineering program, there is an immediate opportunity to apply them.

Block weekend schedule vs. traditional semester schedule: the weekend block scheduling within the context of a 20 month program gives a student the opportunity to intensely focus on a content area with faculty in a cohesively designed educational experience. The duration of the weekend program, like at University of Virginia, provides the total learning of a professional to be woven together by the support of faculty. Block scheduling affords several design choices in a curriculum, most notably with respect to a richer quality of interaction between the students with the faculty in the classroom and the alternative methods to provide feedback and evaluate a student.

Cohort and team based learning vs. individual learning: the weekend format of the System Engineering program provides the opportunity for a group of professionals to develop their expertise with other professionals. Most high level decisions and complex problems require the integration of the work and input of several people. Therefore a student builds experience in this critical skill throughout the program and with the continuity of a single cohort during the 20-month experience.

Systems methodology infused vs. individual content driven: systems engineering provides a foundation in systems methodology that integrates analytical skills, technologies and applications in both settings. However, in the context of the weekend format a student has the opportunity to apply the methodology and skills together to make decisions and address the priorities of the organization throughout the program. 
Specialized graduate level courses in a traditional semester program can introduce specific skills that may not become relevant for several semesters, which may be a drawback to working professionals. During the weekend format, there is a consistency and deepening through each of the courses of the systems methodology that is supported by the cohort, as well as professors through each content area. The integration of the curriculum in the traditional format is left to the individual student with a respective research faculty.

\section{Detailed Learning Environment Comparisons}

Some general differences between the two program formats are based on the vision of the learning objectives, stakeholders in learning, structure and use of class time, presence of technology, use of case-based learning and team-oriented problem solving. Some of these characteristics, such as the use of cases with team-oriented learning work to complement and support each other. Ideally, a different class culture is developed that is more dynamic and cohesive.

Summary Comparison: Educational vision and program structure

\begin{tabular}{|l|l|l|}
\hline Attribute/Outcome & Weekend Format & Traditional Format \\
\hline $\begin{array}{l}\text { Objectives of overall } \\
\text { Master's Program }\end{array}$ & $\begin{array}{l}\text { Student's focus is collaborative } \\
\text { with company development }\end{array}$ & $\begin{array}{l}\text { Student's focus is personal } \\
\text { development }\end{array}$ \\
\hline $\begin{array}{l}\text { Vision of Curriculum } \\
\text { Design }\end{array}$ & $\begin{array}{l}\text { Focused to meet industry/student } \\
\text { needs while maintain academic } \\
\text { standards }\end{array}$ & $\begin{array}{l}\text { Focused to meet academic } \\
\text { standards \& research objectives } \\
\text { while industry/student needs }\end{array}$ \\
\hline Interaction with Industry & Direct & General \\
\hline Class Size & Smaller (20-30 students) & Larger (25-50 students) \\
\hline Class Duration & 8 hour per day - 2 consecutive days & 50-75 minutes per class \\
\hline Class Interval & Every other week & Twice a week \\
\hline Concurrent Courses & $\begin{array}{l}\text { 1-2 courses } \\
\text { Work responsibilities }\end{array}$ & $\begin{array}{l}\text { 2-3 courses } \\
\text { Research interests }\end{array}$ \\
\hline $\begin{array}{l}\text { Development of } \\
\text { Consistent Methodology }\end{array}$ & $\begin{array}{l}\text { More consistent and deepening } \\
\text { through each courses } \\
\text { Supported by cohort and professors } \\
\text { throughout content areas }\end{array}$ & $\begin{array}{l}\text { More individual variability } \\
\text { between coursework } \\
\text { Supported by professor through } \\
\text { research projects }\end{array}$ \\
\hline $\begin{array}{l}\text { Integration of Course } \\
\text { Content }\end{array}$ & $\begin{array}{l}\text { Less formally divided by course } \\
\text { Cumulative process acquiring of } \\
\text { theory \& skill }\end{array}$ & $\begin{array}{l}\text { More rigidly divided by course } \\
\text { Sequential process of acquiring } \\
\text { theory \& skill }\end{array}$ \\
\hline
\end{tabular}

By design the students in the Executive Master's Degree Program are working full time sponsored by their respective company for the duration of the program and bring work related questions into the class discussions. Primary contact with the professor is within the context of the class lecture and discussion; however, the professors hold phone and e-mail office hours and each class has a web page for assignments, supporting materials, and bulletin board discussions. Furthermore, the residential component of the program affords the greatest opportunities for cohort interaction and team building. A significant dimension of the cohort culture is developed through these less-structured 
contacts and serves to create a familiar environment to bring complex ongoing work related questions to the cohort.

Several key characteristics of this learning environment are constrained by the use of time, namely having two days of eight consecutive hours of time with the professor and with the cohort, usually involving lectures, case studies, and group discussions with individual write ups of the material and individual learning. Throughout the day students break out in teams to work on collaborative learning modules, during which time the instructor visits each of the teams to monitor progress and offer guidance and insight.

Summary Comparison: Use of time and technology and impact to content

In the Spring 2000 a course in Data Mining was observed both in the on-grounds setting and within the context of the Executive Master's Program to better understand the enactment of a specific content area with the different formats. In addition to the focus on case-based learning, other questions relating to use of time, technology and establishment of a cohort were investigated. The following are some of the observable similarities and differences when the same content with the same professor was presented and integrated in this course.

\begin{tabular}{|l|l|l|}
\hline Attribute/Outcome & Weekend Format & Traditional Format \\
\hline Use of Class Time & $\begin{array}{l}\text { Lecture + Case Work + Discussion } \\
\text { Lecture }\end{array}$ & Lecture + Discussion \\
\hline $\begin{array}{l}\text { Use of In-Class } \\
\text { Technology }\end{array}$ & $\begin{array}{l}\text { Faculty and students have Lab- tops } \\
\text { Used interactively to solve } \\
\text { problems w/software applications }\end{array}$ & $\begin{array}{l}\text { Faculty for lecture presentations } \\
\text { Used to demonstrate applications }\end{array}$ \\
\hline Use of Internet & $\begin{array}{l}\text { Frequent tool for ongoing } \\
\text { communication with cohort } \\
\text { Making content available }\end{array}$ & $\begin{array}{l}\text { Intermittent and variant tool for } \\
\text { communication with class }\end{array}$ \\
\hline Content of Lecture & $\begin{array}{l}\text { More concise lecture up-front } \\
\text { Theory referenced } \\
\text { Concurrent to Case Assignments } \\
\text { More thorough explanation and } \\
\text { development throughout topic area }\end{array}$ & $\begin{array}{l}\text { More detailed lecture up-front } \\
\text { Theory derived } \\
\text { Sequential to Assignments \& } \\
\text { Discussions } \\
\text { Briefer exploration in class of } \\
\text { individual topics }\end{array}$ \\
\hline Breadth of Content & Smaller range of topics & Greater range of topics \\
\hline Depth of Content & Richer exploration of applications & Deeper exploration of theories \\
\hline Use of Case Studies & Team learning process & $\begin{array}{l}\text { Individual learning \& assessment } \\
\text { Some teamwork }\end{array}$ \\
\hline Presentation of Cases & Verbal discussion & Written presentation \\
\hline
\end{tabular}

Case-based learning is a key features in the design and enactment of a curriculum that offers some of the possibilities in the weekend format. Engineering schools have long focused on instilling a strong foundation of mathematics and the engineering sciences in their students, and have often neglected developing the communication, decision-making, and teamwork skills so vital in industry ${ }^{34}$. One expected learning outcome to engage a learner to be more active and participatory in the classroom ${ }^{5}$. The 
use of this type of learning tool presents several differences to the traditional model of the lecture, problem set, and test. In a case discussion you are drawing more from inductive observation and experience versus following a deductive process as dictated by a codified algorithm, a text or a professor. This serves to provide a different quality of learning for a professional.

Velenchik discusses two classes on economic policy analysis, one case-based, and the other a traditional lecture driven class ${ }^{6}$. She explains that for a more theory oriented course, the traditional approach allows greater coverage of concepts due to the organization and efficiency of lectures. However, students in the case course had a better grasp of the theory that was taught, and were much more successful applying theory and formal models to solve real problems. If the ultimate goal is to produce engineers that solve problems, rather than memorize theory, the value of the case method is evident. Carlson and Schodt provide similar insights based on two courses on Economic Theory ${ }^{7}$.

Wallace and Weiner from MIT examined the introduction of web-based lectures and the shift in lecture content and presentation ${ }^{8}$. Pedagogically the effects on lecture content and style are similar between web-based lectures and the use of time in weekend format. Their findings support the quality of learning by alternate class time use. As technology becomes a more available tool to communicate content, the time and expertise of the faculty may be more available for deeper facilitation of the student's application of the content to real world contexts.

Summary Comparison: Teaching and Learning Styles

\begin{tabular}{|l|l|l|}
\hline Attribute/Outcome & Weekend Format & Traditional Format \\
\hline Class Culture & $\begin{array}{l}\text { Established by cohort } \\
\text { More consistent between courses }\end{array}$ & $\begin{array}{l}\text { Established by professor } \\
\text { Varies by course }\end{array}$ \\
\hline Use of Class Time & $\begin{array}{l}\text { Lecture + Case Work + Discussion } \\
\text { + Lecture }\end{array}$ & Lecture + Discussion \\
\hline Presentation of Cases & Verbal discussion & Written presentation \\
\hline $\begin{array}{l}\text { Revealing of Student } \\
\text { Learning }\end{array}$ & $\begin{array}{l}\text { Discussion as Learning Process } \\
\text { Write up as Individual Reflection }\end{array}$ & $\begin{array}{l}\text { Write up as Individual Process } \\
\text { Group Discussion as Reflection }\end{array}$ \\
\hline Feedback while learning & $\begin{array}{l}\text { Real-time } \\
\text { Frequent while learning from peers, } \\
\text { professors, TAs } \\
\text { Immediate responses from } \\
\text { Professor and again on reflection }\end{array}$ & $\begin{array}{l}\text { Delayed } \\
\text { Limited between peers } \\
\text { 1-to-1 w/ professor or TA outside } \\
\text { class } \\
\text { Delayed responses on submissions }\end{array}$ \\
\hline Student Assessment & $\begin{array}{l}\text { Both verbal and written equal } \\
\text { Usually same as feedback } \\
\text { Mostly written presentations }\end{array}$ \\
\hline Teaching Style & $\begin{array}{l}\text { More Conversational } \\
\text { Less Pre-determined } \\
\text { More response to students in room }\end{array}$ & $\begin{array}{l}\text { More Formal } \\
\text { More determined class to class } \\
\text { Less response to students in room }\end{array}$ \\
\hline Role of Professor & $\begin{array}{l}\text { Provide insights into expertise } \\
\text { Revealing of thought process }\end{array}$ & $\begin{array}{l}\text { Clarify content presented } \\
\text { Inquiry to student thought process }\end{array}$ \\
\hline $\begin{array}{l}\text { Ronsistent throughout courses } \\
\text { Assistants }\end{array}$ & $\begin{array}{l}\text { Varies by class } \\
\text { Involvement typically outside of } \\
\text { class - Q\&A }\end{array}$ \\
\hline
\end{tabular}

Proceedings of the 2001 American Society for Engineering Education Annual Conference \& Exposition Copyright (C) 2001, American Society for Engineering Education 


\begin{tabular}{|l|l|l|}
\hline & & Often grades presentations \\
\hline Interaction between & Group problem solving & Mostly peer review \\
Students & Strong team building \& interactions & Some team building \\
& Greater collaboration & Greater individualism \\
\hline Involvement of Student & Responsibility to contribute & Participation is personal \\
& Generally active learning & Generally passive learning \\
\hline
\end{tabular}

In the weekend format, assessment is made on the development and communication of the methodology and skills, both in relationship to the ongoing conversation in the classroom and in written presentation to the faculty. However, there is a greater attention made to the student's engagement in class discussions, with confirmation of assessment in individual written presentations. Therefore, the time frame in which feedback is offered from both colleagues and the professor is different in each setting. In a weekend format class discussion feedback from the professor is almost immediate, whereas in a traditional course the expected length of time a problem set is returned with professor comments is at least a week.

One consideration in the successfully use of the weekend format is the size of the cohort. The quality and depth of communication required for the kind of learning environment requires a sufficiently small number of students. The issue is to find an optimal number of students a professor can reasonably facilitate, observe, and evaluate during the course of the class sessions. Whereas in a traditional classroom, more students can be present for the lecture, additionally assessment is made more on individual written performance and less on class participation.

Although many of the same cases were used in different formats to illustrate the same content, the enactment of the case in each format was different. For instance, the process on-grounds of using cases were to individually apply the theory and work through the problems, write up the findings and then the professor to lead a discussion the problem to the group. In contrast, the weekend version format was to discuss the problem in small group, apply theory and develop solutions within the group context and then to write up the case individually. While both processes consist of similar elements, the difference in the sequencing offers two very different kinds of the learning experiences.

As noted above, the students enrolled in the two programs have different professional objectives. The learning environment in the weekend format is geared to support interpersonal verbal communication where as the traditional program supports individual written communication. Given trends in the needs of business the former learning environment would build the kinds of skills that are necessary to be competitive in a fast paced and complex work setting.

Further research

As technology continues to develop at a rapid pace, more leaders with strong technical skills, not less, are needed in industry. The responsibility to develop these leaders falls squarely on the shoulders of engineering institutions across the country ${ }^{9}$. 
Industry expects problems of increased complexity that requires expertise from several disciplines for sound decision-making. Thus a typical technological context will require the meaningful collaboration of several experts. Some of this research may serve to support changes within traditional academic settings, as the learning objectives of the students and the industrial culture changes.

Several specific elements comprise the core of the weekend format as described in this paper. Each of the elements could be the foundation of further research in engineering education. Specifically, the implementation of cohort learning to greater team cooperation and industry development would be worthy of empirical validation, along with the "accuracy" of using alternative evaluation methods in combination with the discussed teaching methods.

The weekend format Master's Degree Programs relies on current analytical and technical cases. The development of a richer library of cases designed for engineering content is clearly needed. Development of specific engineering case studies will support both faculty and students, since this activity would both deepen the relationship between industry and academia, as well as provide greater choices in designing program curriculum.

A fundamental dimension to the continued success of weekend format programs is the readiness of professors from a more traditional teaching style to embrace the more dynamic and less deterministic learning environment. Hand-in-hand with the influx of greater technology use in the classroom, faculty will need time and support to translate codified and familiar content into alternate formats. Looking to other weekend format degree programs that are designed for working professionals, the engaging of students with specific industrial objectives do require a shift in traditional lecture teaching styles

10. In combination with the cases which are highly dependant on quality interaction with faculty, a complementary set of research could include the development of various instructional tools for computer based lectures or multi-media presentation of content to support the learning objectives of all stakeholders in a timely manner.

\section{Conclusions}

The implementation of the weekend format is still a relatively new conceptual pedagogical framework. Much of the strength of the weekend format as implemented by the Systems Engineering Department at University of Virginia can be contributed to synergistic qualities of a single cohort, block-scheduled time, team and case-based learning with courses offered in alternating weekend over two years. A Master's Degree Program with a weekend format can support thorough development of a cohesive methodological approach, as well as technical and analytical rich content. The interrelationship of learning objectives of the professional development of the student, the interest of the industrial sponsor and the larger mission of academic universities are all supported by the Master's Program in a weekend-format. This model offers the possibility of a broader array of choices in curriculum design that may be applied to other engineering disciplines, as well as more traditional structured degree programs. These 
observations are not conclusive, but serve to pose ongoing research questions for the engineering education community.

CARRIE GIRSTANTAS received her B.S. in Systems Engineering and Environmental Sciences (1991) from the University of Virginia. She has been a teacher and educational consultant to high schools specializing problem solving and math fundamentals as well as whole brain learning. She was a program assistant for the Executive Master's Degree Program at UVa during 1999 and 2000. Currently, she is pursuing her PhD. Degree in Systems Engineering with research interests in engineering education, youth violence, and sustainable community development.

DR. WILLIAM T. SCHERER received his PhD. degree in Systems Engineering from the University of Virginia. He has taught at the UVa Department of Systems Engineering since 1986, developing and offering undergraduate and graduate courses in systems engineering methodology, engineering design, decision analysis, stochastic control, and operations research. His current research interests include Intelligent Transportation Systems, Markov decision processes, systems engineering methodologies, and engineering education.

1 Gorman, M., Richards, L., Scherer, W., and Kagiwada, J., "Teaching Invention and Design: MultiDisciplinary Learning Modules," ASEE Journal of Engineering Education, April 1995, pp. 175-186.

2 “ASEE Project Report: Engineering Education for a Changing World”, ASEE Prizm, December, 1994, 20-27.

3 Masi, C.G., "Re-engineering Engineering Education", IEEE Spectrum, September, 1995, 44-47.

${ }^{4}$ Ladesic, J.G., and D.C. Hazen, “A Course Correction for Engineering Education”, Aerospace America, May, 1995, 22-27.

${ }^{5}$ Richards, L.G., M.E. Gorman, W.T. Scherer, R.D. Landel, "Promoting Active Learning with Cases and Instructional Modules", Journal of Engineering Education, October, 1995.

${ }^{6}$ Velenchik, Ann D., "The Case Method as a Strategy for Teaching Policy Analysis to Undergraduates," The Journal of Economic Education, Vol. 26, Winter 1995, 2938 .

${ }^{7}$ Carlson, John A. and David W. Schodt. "Beyond the Lecture: Case Teaching and the Learning of Economic Theory.", The Journal of Economic Education, Vol. 26, Winter 1995, 17-28.

${ }^{8}$ Wallace, D., Weiner, S., "How might Classroom Time be Used Given WWW-Based Lectures?", ASEE Journal of Engineering Education, July 1998, pp. 237 - 248.

${ }^{9}$ Felder, R. M., "Does Engineering Education Have Anything to Do With Either", Journal of Engineering Education, Vol. 75, November, 1984, 95-99.

${ }^{10}$ Chelst, K., Falkenburg, D., Nagle, D., “An Industry-Based Engineering Management Master's Program for the Working Engineer,” ASEE Journal of Engineering Education, July 1998, pp. 289 - 296.

Proceedings of the 2001 American Society for Engineering Education Annual Conference \& Exposition Copyright $\odot$ 2001, American Society for Engineering Education 